\title{
Relationship between blood superoxide dismutase activity and zinc, copper, glutathione and metallothioneines concentrations in calves
}

\author{
Vladimir Safonov*, Vadim Ermakov*, Valentina Danilova*, Vyacheslav Yakimenko ${ }^{\dagger}$ \\ *Vernadsky Institute of Geochemistry and Analytical Chemistry \\ Moscow, Russian Federation \\ safonovladimir8@rambler.ru, vad.ermakov@rambler.ru, valentina_danilova142@rambler.ru \\ $\dagger$ Voronezh State Agricultural University named after Emperor Peter the Great \\ Voronezh, Russian Federation \\ yakimenko0987@rambler.ru
}

Received: 29 July 2021, accepted: 24 November 2021, published: 28 December 2021

\begin{abstract}
RedOx (reduction-oxidation) processes determine the resistance of the organism to pollutants. The aim of the study was to establish a possible relationship between copper and zinc concentration in the blood of calves and the enzyme activity of superoxide dismutase. The study was conducted in 2019 on 20 calves with a weight of 201$250 \mathrm{~kg}$. The samples of venous blood were taken to estimate the level of hemoglobin, glutathione, metallothioneins, as well as zinc, copper, and superoxide dismutase activity. The obtained average values of these substances' concentrations were compared between each other. A positive correlation between the activity of superoxide dismutase and the concentration of zinc $(r=0.64)$ and copper $(r=0.87)$ in the blood of calves has been established. It may be because both metals are obligatory components
\end{abstract}

of superoxide dismutase. There is also a positive relationship between the levels of copper and zinc $(r=0.68)$. For the other parameters, no reliable relationship was found. The data obtained indicate a positive relationship between superoxide dismutase activity and metal concentrations of copper and zinc in the blood of calves. At the same time, a more significant positive relationship is established for copper.

Keywords- antioxidant system; calves; metallothioneins; superoxide dismutase

\section{INTRODUCTION}

Among all the metabolic processes occurring in animals, one of the key roles is assigned to reduction-oxidation (redox) processes intended

Copyright: (C) 2021 Safonov et al. This article is distributed under the terms of the Creative Commons Attribution License (CC BY 4.0), which permits unrestricted use, distribution, and reproduction in any medium, provided the original author and source are credited.

Citation: Vladimir Safonov, Vadim Ermakov, Valentina Danilova, Vyacheslav Yakimenko, Relationship between blood superoxide dismutase activity and zinc, copper, glutathione and metallothioneines 
to meet the body's energy needs. Additionally, redox processes determine oxygen delivery and utilization in the tissues. Therefore, oxygen radicals are constantly formed in the body, being quenched/scavenged by endogenous and exogenous antioxidants that maintain homeostasis. Increased concentration of oxygen radicals can lead to lipid peroxidation (LPO), leading to negative effects, which manifests in various kinds of damage to cell membranes, organelles (lysosomes), or functional cells (erythrocytes). Given the critical functions performed by membranes, organelles, and erythrocytes, the negative impact of excessive LPO should not be underestimated [1].

At the cellular level, the negative effect is expressed in structural and irreversible changes of cell membranes, leading to the death of a single cell, entire tissue, or even the entire organism. Another negative characteristic of LPOs excessive concentrations is the disruption of such a vital process as cellular respiration. In particular, primary LPO products (diene conjugates) are toxic metabolites, contributing to the damage of such macromolecules as proteins, enzymes, nucleic acids, and lipoproteins. Another type of LPO product includes aldehydes and ketone bodies, such as malonic dialdehyde. These compounds are involved in the synthesis of prostaglandins and steroids (progesterone, etc.). The reaction between dialdehydes and free groups of membrane compounds results in the formation of peroxidation end products, such as Schiff base. If the formation of such products is prolonged, their concentration increases, and their interaction with free groups of membrane compounds eventually leads to membrane destruction and the death of cells [2].

Three groups of antioxidation factors were distinguished: 1) enzymes such as superoxide dismutase, catalase, and glutathione peroxidase); 2) proteins, which include ferritin, ceruloplasmin, transferrin, and albumin; and 3) low-molecularweight compounds such as vitamins (E, C, A) and other compounds (ubiquinone, carotenoids, acetylcysteine, and alipoic acid) [3]. Due to the heterogeneity of the antioxidant factors, the mechanisms that regulate oxidative activity are different. In particular, superoxide dismutase has an inactivating effect on the superoxide anion as it contains metal ions at varying valence ratios. Such metals include zinc, magnesium, copper, and manganese [4].

Another enzyme, catalase, plays a crucial role in preventing the accumulation of hydrogen peroxide excess in cells. The latter is formed by aerobic oxidation of reduced flavoproteins. Of extreme importance for studying the physiological processes occurring during the first postnatal development stages in young cattle is understanding the fight against excessive peroxidation product concentration, which may provoke the development of various pathologies [5].

There is another connection between antioxidant enzymes and micronutrients (zinc, copper, manganese, selenium), since the micronutrients mentioned above are a part of the enzymes. In particular, the active center of superoxide dismutase contains copper and manganese. Superoxide dismutase, in turn, is one of the main components of the antioxidant system [6].

Free radicals are well-known leading players in the pathogenesis of more than one hundred diseases when in increased concentration [7]. Most of these diseases are otherwise associated with the adverse effects of environmental factors or aging processes. The increased reactivity of free radicals is associated with the presence of a freeelectron on the outer orbital of an atom. When free radicals inside the body react with macromolecules on the surface of cell membranes, the latter is destroyed. Negative effects of free radicals are linked to the processes that occur in cells, such as protein phosphorylation, as well as cell proliferation or DNA transcription in cell nuclei. In organs, free radicals are involved in the regulation of vascular tone. In case of increased concentration of free radicals, the synthesis of prostaglandins and metalloproteins, together with growth factors, are activated. Usually, only up to $5 \%$ of the oxygen used by the body is converted into free radicals. Some of them, such as nitric oxide (NO), can exhibit antioxidant properties [8]. 
V Safonov, V Ermakov, V Danilova, V Yakimenko, Relationship between blood superoxide dismutase ...

It is known that, when blocking highly toxic oxygen radicals formed in the process of oxygen metabolism, the enzyme superoxide dismutase (SOD, EC 1.15.1.1) plays a significant role. It belongs to the group of antioxidant enzymes that catalyzes superoxide dismutation to oxygen and hydrogen peroxide and also prevents oxidation of several biologically active substances [9-11]. SOD activity determination in the blood of animal species and humans possesses important diagnostic value in developing various pathologies $[12,13]$.

SOD is a metalloprotein that catalyzes the conversion of the highly active superoxide radical into less active hydrogen peroxide. Three varieties of the enzyme are distinguished by the level of iron, copper, zinc, or magnesium ions [14]. Copper and zinc levels play a major role in SOD activity. The study of physiological processes, including redox reactions, is equally essential for both medicine and veterinary medicine. Furthermore, the results obtained in veterinary medicine can be extrapolated to medicine, following similar experiments. At the same time, there have been no studies in which the role of superoxide dismutase and copper/zinc concentrations in blood have been considered and compared simultaneously.

This determined the relevance of the present work. The blood of calves was analyzed to establish the relationship between the concentration of copper and zinc on the one hand, and the activity of superoxide dismutase on the other. The authors suggest that these parameters are more directly related to copper than to zinc.

This work aimed to define the existence of a relationship between the concentration of copper and zinc in the blood of calves and the activity of the enzyme superoxide dismutase.

Considering that an insufficient number of data on the copper and zinc concentrations and SOD activity comparison is available, we evaluated this interaction by analyzing the blood of calves. In addition, this study took into account the total glutathione and metallothioneins content in the blood of animal species determined by liquid chromatography and derivatization thereof using
N-9 (acridinyl) maleimide.

\section{MAterials AND METHODS}

\section{A. Materials}

The study was carried in 2019 out at the Liskinskiy APC, Liskinskiy District, Voronezh Region in Russia. Young cattle species were selected weighing 201-250 kg. The study enrolled 20 animals. Animal species received a ration consisting of 25 $\mathrm{kg}$ of silage, $2 \mathrm{~kg}$ of straw and $1.8 \mathrm{~kg}$ of combined feed.

Venous blood samples for laboratory tests were taken from animal species in the morning before feeding. Vacuum tubes with EDTA-Na were used for the whole blood samples.

All international and national guidelines for the care and use of animals were followed. The study complies with the relevant ethical standards. It was approved at the Ethical Committee's meeting of Voronezh State Agricultural University named after Emperor Peter the Great (Minutes of the meeting No. 554).

\section{B. Analytical Methods}

When determining hemoglobin content, $20 \mu \mathrm{l}$ of blood were added to $4 \mathrm{ml}$ of $0.04 \% \mathrm{NH} 4 \mathrm{OH}$, and the contents were mixed by shaking for 5 minutes. After one hour, solution absorbance was measured at $523 \mathrm{~nm}$ in cuvettes with an optical path length of $1 \mathrm{~cm}$ using the 320 spectrophotometer (Hitachi). Hemoglobin content was identified according to the hemoglobin standard calibration chart (Sigma 08449 hemoglobin from bovine blood). This method is described in the article [15].

SOD activity in whole blood with heparin was evaluated by the adrenaline auto-oxidation method $[16,17]$ after the erythrocytes separation, washing thereof with $0.9 \%$ cold sodium chloride solution, and hemolysis at $1-4^{\circ} \mathrm{C}$ for $15 \mathrm{~min}$ utes. Absorption alteration was observed at 347 $\mathrm{nm}$ in the 320 spectrophotometers temperaturecontrolled cuvette.

Copper and zinc concentrations in blood were determined by atomic absorption spectroscopy (AAS) in the flame version using the CORTEC 
LLC certified device after blood mineralization with a mixture of nitric and perchloric acids.

Glutathione and metallothioneins content was determined by low-pressure liquid chromatography using a device with Shimadzu spectrofluorometric detector in the form of fluorescent complexes after the reaction of SH-groups with $\mathrm{N}$-(9-acridinyl) maleimide (NAM) in columns with polymeric sorbents [18]. In this case, blood samples were mixed with an equal portion of methanol, and the clear supernatant fluid was used for analysis after homogenization and centrifugation. SS groups restoration to $\mathrm{SH}$ groups was carried out with sodium borohydride in the nitrogen atmosphere at $50^{\circ} \mathrm{C}$.

\section{Statistical Analysis}

Study results were processed by the variation analysis method using Ms-Excel 2013 software program The arithmetic mean and error of the mean were calculated for each of the studied parameters, i.e., superoxide dismutase activity, copper and zinc concentrations, glutathione, and metallothioneins. Also, the variability from minimum to maximum for each of these parameters was indicated. The concentration of the studied parameters was established depending on the hemoglobin level. The correlations between the parameters, i.e., how the concentration of one compound is related to that of another (Pearson correlations) was stated as well. At that, correlations greater than 0.50 were considered significant. A $p \leq 0.05$ was taken as the baseline level of significantly different data. The data were tested for normality (test for distribution normality). The obtained results allowed stating that the distribution of parameters corresponded to normal, specifying parametric analysis.

\section{RESULTS}

Data on the calves' blood components content and SOD activity are presented in Table 1. Hemoglobin content in the blood of the clinically healthy calves varied from 104.8 to $151.7 \mathrm{~g} / \mathrm{l}$ with an average of $129.2 \pm 10.9 \mathrm{~g} / \mathrm{l}$, which is considered a physiological norm. Ten animal species out of 20 had hemoglobin levels approaching the $120 \mathrm{~g} / \mathrm{l}$ indicators. Hemoprotein content of 107-116 mg/l was found only with three calves.

SOD activity (in hemoglobin units/mg) varied from 0.80 to 1.51 units, but in most cases was approaching the 1 indicator $(0.99 \pm 0.11)$. Zinc concentration in the calves' blood was noticeably varying and ranging from 1.50 to $4.58 \mathrm{mg} / \mathrm{l}$. On average, zinc content in the calves' blood was $2.60 \pm 0.60 \mathrm{mg} / \mathrm{l}$. Variation range reached 3 units. However, the maximum zinc concentration in blood was found only with one calf (4.58 and averaging at $1.08 \pm 0.22 \mathrm{mg} / \mathrm{l}$. The average copper concentration value in the calves' blood approached the most common trace element content in the blood of terrestrial mammals.

Table 1 also presents the results of studies on the content of total glutathione and metallothioneins in the calves' blood. Glutathione content varies from 80.3 to $255.2 \mathrm{mg} / \mathrm{l}$, i.e., in 3 times, as in the case of trace elements. This indicates a significant difference in metabolic processes with rapidly growing animal species.

Data on MT concentration in the calves' blood is presented for the first time. MT average content in the calves' blood is $13.3 \pm 2.8 \mathrm{mg} / \mathrm{l}$. This low molecular weight metalloprotein content is significantly lower than that of glutathione and varies from 7.9 to $19.6 \mathrm{mg} / \mathrm{l}$. The relationship between the content of separate blood components with calves is demonstrated in Table 2. Significant positive correlation between SOD activity and zinc $(r=0.64)$ and especially copper $(r=0.87)$ concentrations in the blood of the young animal species is noteworthy. In all likelihood, this is because both trace elements are the SOD essential components $[12,11]$. At the same time, the relationship between the level of copper and zinc is also significant $(r=0.68)$.

Correlation between SOD activity and glutathione and MT content level was not observed. However, such a relationship exists between glutathione and MT concentrations, which seems to be determined by the difference in metabolic processes of these biologically active components. 
V Safonov, V Ermakov, V Danilova, V Yakimenko, Relationship between blood superoxide dismutase ...

TABLE I

HEMOGLOBIN, ZINC, COPPER, GLUTATHIONE, AND METALLOTHIONEINS CONTENT AND SOD ACTIVITY IN THE CALVES' BLOOD

\begin{tabular}{lllllll}
\hline $\begin{array}{l}\mathrm{Hb}, \\
g / l\end{array}$ & $\begin{array}{l}\text { SOD activity, } \\
\text { Hb unit } m g\end{array}$ & $\begin{array}{l}\mathrm{Zn}, \\
\mathrm{mg} / \mathrm{l}\end{array}$ & $\begin{array}{l}\mathrm{Cu}, \\
m g / l\end{array}$ & $\begin{array}{l}\mathrm{Gl}, \\
m g / l\end{array}$ & $\begin{array}{l}\mathrm{MT}, \\
m g / l\end{array}$ & $\begin{array}{l}\text { Weight } \\
\text { of the } \\
\text { calves }\end{array}$ \\
\hline 142.6 & 0.86 & 1.99 & 0.82 & 255.2 & 19.2 & 208 \\
121.0 & 0.94 & 2.71 & 0.88 & 185.4 & 12.5 & 224 \\
151.2 & 0.94 & 3.61 & 1.05 & 176 & 15.4 & 212 \\
149.0 & 0.88 & 2.36 & 1.00 & 129.9 & 7.9 & 239 \\
126.4 & 0.83 & 1.88 & 0.98 & 140.8 & 12.1 & 241 \\
151.7 & 0.85 & 1.55 & 0.92 & 171.5 & 12.9 & 207 \\
126.9 & 0.94 & 2.49 & 0.98 & 116.5 & 11.3 & 222 \\
125.3 & 0.96 & 2.15 & 0.90 & 131.2 & 9.6 & 245 \\
151.7 & 0.93 & 3.36 & 1.16 & 80.3 & 9.6 & 237 \\
118.3 & 0.80 & 1.50 & 0.62 & 178.1 & 16.6 & 201 \\
129.6 & 0.85 & 2.31 & 1.11 & 153.4 & 19.6 & 203 \\
117.2 & 0.90 & 2.45 & 1.02 & 96.0 & 10.4 & 228 \\
123.7 & 1.06 & 1.98 & 0.87 & 117.3 & 12.5 & 216 \\
140.4 & 0.98 & 1.99 & 1.03 & 156 & 9.4 & 238 \\
123.7 & 0.94 & 2.29 & 1.05 & 132.2 & 11.3 & 249 \\
131.8 & 1.03 & 2.92 & 0.78 & 158.4 & 15 & 209 \\
104.8 & 0.90 & 3.26 & 0.96 & 123.2 & 13.4 & 234 \\
115.6 & 1.51 & 3.90 & 2.18 & 94.4 & 10.8 & 243 \\
106.9 & 1.21 & 4.58 & 1.68 & 99.3 & 17 & 239 \\
126.9 & 1.19 & 2.70 & 1.57 & 184.3 & 19.1 & 215 \\
Averages & M m $)$ & & & & & \\
$129.2 \pm$ & $0.98 \pm$ & $2.60 \pm$ & $1.08 \pm$ & $144.0 \pm$ & $13.3 \pm$ & \\
10.9 & 0.11 & 0.60 & 0.22 & 32.3 & 2.8 & \\
\hline
\end{tabular}

Legend: $\mathrm{Hb}$ - hemoglobin, Gl - glutathione, MT - metallothioneins, $\mathrm{Zn}$ - zinc, $\mathrm{Cu}$ - copper.

The velocity constant in the reaction of MTs with hydroxyl radicals is 2 orders of magnitude higher than that of glutathione.

The regression model showed that MT concentration increased significantly with calf body weight (Fig. 1). A positive trend in the regression was observed between weight and SOD activity, with zinc concentration tending to increase (Fig.
2). However, a negative trend was observed for MT concentration (Fig. 3). The PCA analysis (Fig. 4) demonstrated that the weight and hemoglobin levels are in different components, indicating their negative relationship. At that, glutathione and MT concentrations are within the same component but at negative levels. It indicates a different direction of the processes involving these substances, 
V Safonov, V Ermakov, V Danilova, V Yakimenko, Relationship between blood superoxide dismutase ...

TABLE II

CORRELATION PARAMETERS BETWEEN CALVES' BLOOD COMPONENTS

\begin{tabular}{|c|c|c|c|c|c|}
\hline $\mathrm{Hb}$ & SOD & $\mathrm{Zn}$ & $\mathrm{Cu}$ & Gl & MT \\
\hline & \multirow[t]{5}{*}{0.348769} & -0.27261 & -0.26462 & 0.31708 & -0.13691 \\
\hline & & 0.638739 & 0.874938 & 0.34148 & 0.000449 \\
\hline & & & 0.684429 & 0.43311 & 0.07109 \\
\hline & & & & 0.40321 & 0.033942 \\
\hline & & & & & 0.585325 \\
\hline
\end{tabular}

Legend: $\mathrm{Hb}$ - hemoglobin, Gl - glutathione, MT - metallothioneins, Zn - zinc, $\mathrm{Cu}$ - copper.

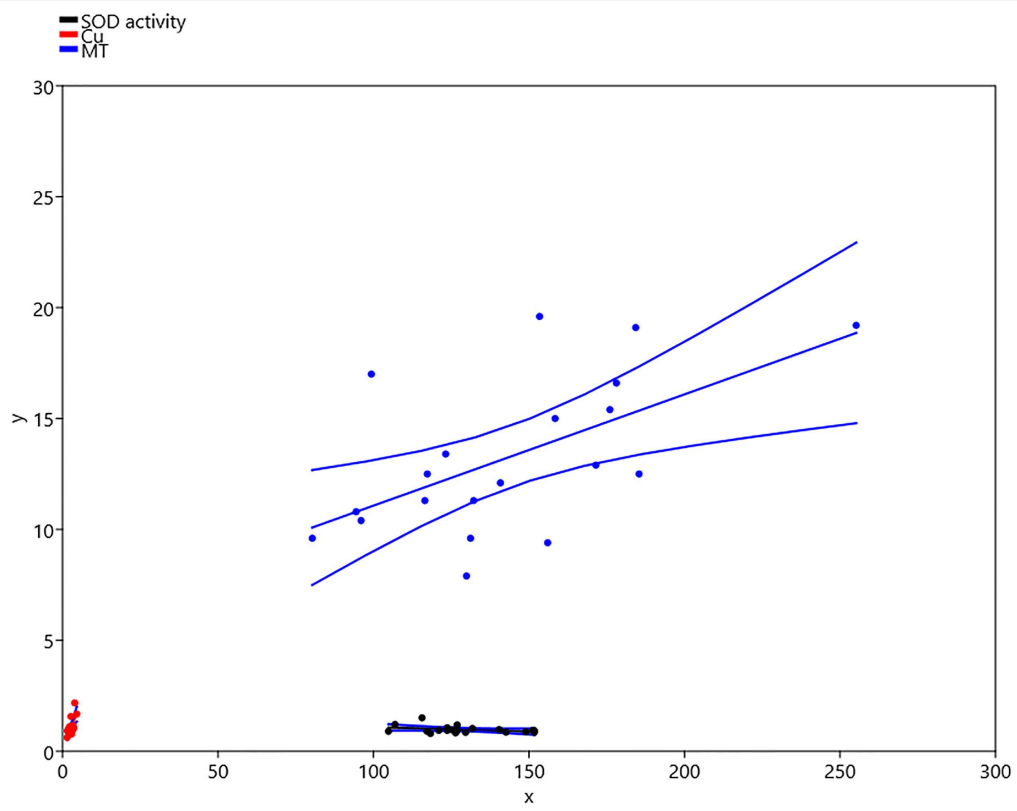

Fig. 1. Regression model for the considered parameters

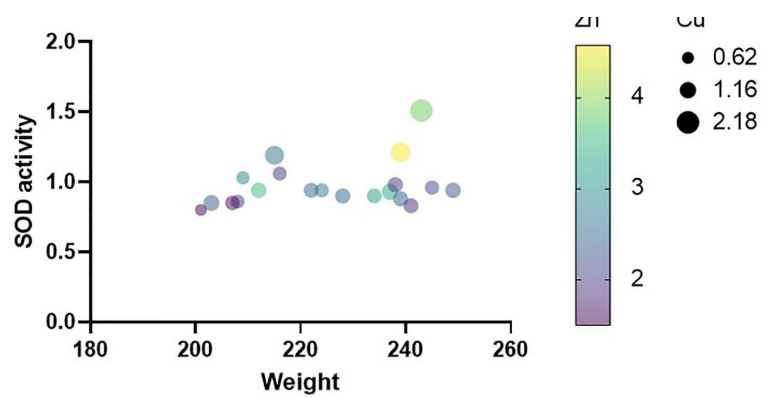

Fig. 2. Linear regression between SOD activity and Weight of the animals, considering zinc and copper concentrations in blood 


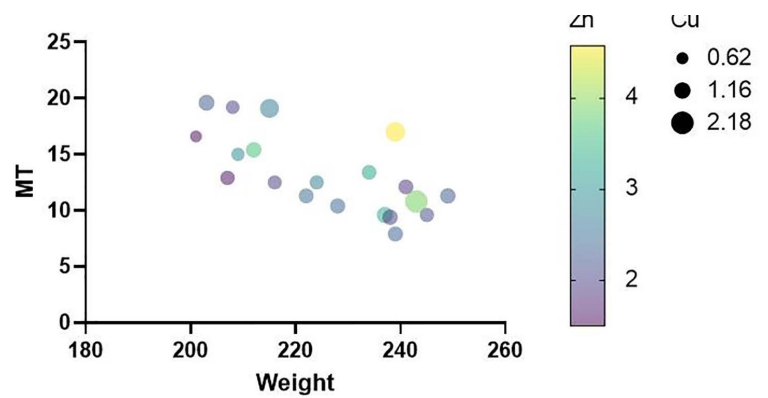

Fig. 3. Linear regression between MT and Weight of the animals, considering zinc and copper concentrations in blood

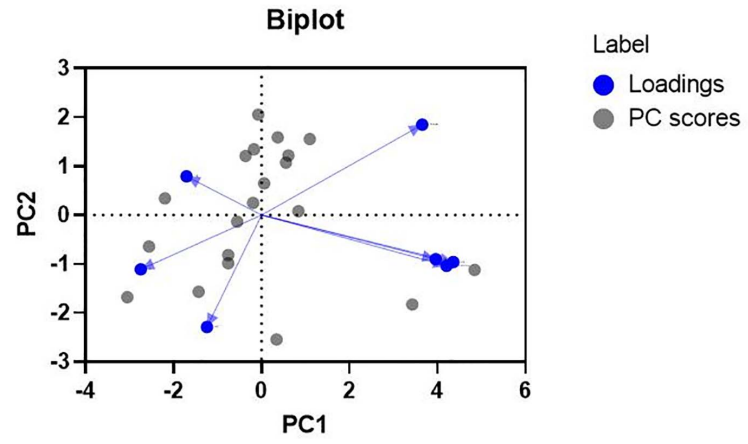

Fig. 4. Results of the PCA analysis for the considered parameters

whereas the activity of SOD is related to weight, which was also illustrated in Fig. 1.

\section{DISCUSSION}

Increasing pollution associated with the anthropogenic factor causes the ingress of heavy metals and radioactive substances from the external environment into the body. Their combined negative impact on various physiological processes, including redox reactions, is becoming increasingly important. When toxicants enter the body in elevated concentrations, free radicals are produced, further increasing the destruction of individual cells, organs, systems, and, eventually, the entire organism [19]. In this connection, the developments related to the pro-oxidant-antioxidant system of the body are highly relevant since the disturbances in the functioning of these systems will determine the possible pathologies. This work is among similar studies devoted to analyzing the protective mechanisms of the antioxidant system, as well as the role of free radicals and thiol compounds in the maintenance of the antioxidant system [20,21]. The relationship between the concentration of copper ions in the blood of calves and the level of superoxide dismutase activity, the most important enzyme in redox reactions, has been demonstrated. At that, the data obtained on an animal object and applicable to veterinary medicine can also be used as a comparison or model in similar medical studies. Thus, this research data can be applied not only in veterinary medicine but also in other disciplines.

Redox reactions play a principal role in metabolism, providing a dynamic equilibrium between catabolism and anabolism and thus, achieving the constancy of physiological processes in the body. The antioxidant system regulates biochemical processes caused by redox reactions. It includes both high molecular weight components (primarily such enzymes as superoxide dismutase, glutathione peroxidase, catalase, and glutathione reductase) and low molecular weight components, particularly vitamins and bioflavonoids [22]. The regulation of redox processes is performed by endogenous thiols, which include $\mathrm{SH}$-groups, as well as thiols and mercaptans. Metallothioneins, glutathione, cysteine, and other compounds are known to be also involved in the regulation process. The interaction of these compounds in the blood has also been considered in this paper, while for metallothioneins, such a study has been performed for the first time. Compounds containing sulfhydryl groups are known to be involved in such important processes as cell division, phosphorylation, peroxidation, and muscle contraction [23]. Sulfhydryl groups constitute hormones, active enzyme centers, and receptors. Thiol compounds' role consists of their protective effect on the functional groups of macromolecules and cell membranes concerning active oxygen radicals. Besides, thiol compounds can form complexes with metal ions, participating in the transport of these ions or the toxicants' neutralization [24]. The metallothioneins considered in this work have the thiol groups of cysteine amino acid residues 
in their composition. They can bind both metals involved in physiological processes (zinc and copper) and toxicant metals (cadmium, mercury, lead, arsenic). Pathological processes of such toxicants accumulation can lead to imbalances in the prooxidant-antioxidant system [25]. In this regard, oxidative stress develops since the thiol-disulfide system responds to internal or external influences by changing the indicators of the redox state [26]. It is also worth mentioning that thiol groups serve as targets when exposed to heavy metals because of their high reactivity. Hence, SH-groups are being blocked, while mercaptides and disulfide bonds are being formed [27]. If disulfide groups are reduced, thiol groups can be regenerated, thus providing antioxidant homeostasis.

\section{CONCLUSIONS}

The data obtained by the authors indicate a definite relationship between SOD activity and copper and zinc trace elements concentration in calves' blood. It should be noted that the most significant relationship is characteristic for copper. Differentiation in the SOD trace elements composition in blood of various animal species in the process of their development could be of interest, as well as existence of a dependence of SOD activity on status of the indicated trace elements in the environment and feed.

As for glutathione and MT, the data obtained indicate a difference in metabolic pathways involving SOD and thiol-containing substances. It is of interest to activate the synthesis thereof under the extreme geochemical conditions facing an excess of metals in the environment and feed of animal species.

\section{ACKNOWLEDGMENT}

The authors are grateful to two anonymous reviewers who have undoubtedly contributed to a considerable improvement in the quality of this article. The research is supported by a grant from the Russian Foundation for Basic Research No. 19-05-00054.

\section{REFERENCES}

[1] G. N. Dantas, B. P. Santarosa, V. H. Santos, H. B. Hooper, R. A. Micai, Y. K. Sinzato, D. C. Damasceno, A. A. da Silva, F. G. Benesi, and R. C. Gonçalves, "Oxidative stress biomarkers in newborn calves: Comparison among artificial insemination, in vitro fertilization and cloning," Anim. Reprod. Sci., vol. 219, p. 106538, 2020. doi: 10.1016/j.anireprosci.2020.106538.

[2] J. Patel, S. S. Chaudhary, A. Dadawala, and V. Patel, "Assessment of oxidative stress by trace elements in pregnant kankrej cows," Int. J. Curr. Microbiol. Appl. Sci., vol. 9(3), pp. 2464-2471, 2020. doi: 10.20546/ijcmas.2020.903.282.

[3] G. N. Dantas, B. P. Santarosa, F. J. Benesi, V. H. Santos, and R. C. Gonçalves, "Clinical and blood gas analysis of calves conceived by artificial insemination, in vitro fertilization and animal cloning," Pesq. Vet. Bras., vol. 39, pp. 485-491, 2019. doi: 10.1590/1678-5150-pvb5971.

[4] A. Pimenta-Oliveira, J. P. Oliveira-Filho, A. Dias, and R. C. Gonçalves, "Morbidity-mortality and performance evaluation of Brahman calves from in vitro embryo production," BMC Vet. Res., vol. 7, p. 79, 2011. doi: 10.1186/1746-6148-7-79.

[5] A. Tyagi, R. Arora, V. S. Rajora, and N. Arora, "Evaluation of antioxidant profile in subclinical mastitis in dairy buffaloes," J. Entomol. Zool. Stud., vol. 8(5), pp. 2256-2259, 2020.

[6] B. Esmaeilnejad, M. Tavassoli, B. Dalir-Naghadeh, A. Samiei, S. Rajabi, V. Mohammadi, E. Anassori, and S. Ehteshamfar, "Status of oxidative stress, trace elements, sialic acid and cholinesterase activity in cattle naturally infected with Babesia bigemina," Comp. Immunol. Microbiol. Infect. Dis., vol. 71, p. 101503, 2020. doi: 10.1016/j.cimid.2020.101503.

[7] L. G. Slivinska, A. R. Shcherbatyy, B. O. Lukashchuk, and B. V. Gutyj, "The state of antioxidant protection system in cows under the influence of heavy metals," Regul. Mech. Biosyst., vol. 11(2), pp. 237-242, 2020. doi: 10.15421/022035.

[8] J. P. Goff, "Invited review: Mineral absorption mechanisms, mineral interactions that affect acid-base and antioxidant status, and diet considerations to improve mineral status," J. Dairy Sci., vol. 101(4), pp. 27632813. doi: $10.3168 /$ jds.2017-13112.

[9] B. Halliwell and J. M. Gutteridge, "Oxygen toxicity, oxygen radical, metals and disease," Biochem. J., vol. 292, pp. 1-14, 1984. doi: 10.1042

[10] V. E. Volykhina and Ye. V. Shafranovskaya, "Superoxide dismutase: structure and properties," Herald Vitebsk State Med. Univ., vol. 8(4), pp. 1-18, 2009.

[11] Y. Wang, R. Branicky, and A. Noë, "Superoxide dismutases: Dual roles in controlling ROS signaling," J. Cell Biol., vol. 217(6), pp. 1915-1928, 2018. doi: 10.1083/jcb.201708007.

[12] V. V. Ermakov, S. F. Tyutikov, and V. A. Safonov, Bio- 
geochemical indication of microelementosis. Moscow: Edition of the Russian Academy of Sciences, 2018.

[13] M. I. Retskiy, S. V. Shabunin, G. N. Bliznetsova, T. E. Rogacheva, T. G. Ermolova, O. Yu. Fomenko, E. V. Bratchenko, V. Yu. Dubovtsev, N. N. Kaverin, and O. I. Tsebrzhinskii, Methodological guidelines for the study of free radical oxidation processes and organism antioxidant protection system. Voronezh: VNIVIPFiT SSI, 2010.

[14] Y. Grymak, O. Skoromna, O. Stadnytska, O. Sobolev, B. Gutyj, S. Shalovylo, Y. Hachak, O. Grabovska, I. Bushueva, G. Denys, V. Hudyma, N. Pakholkiv, I. Jarochovich, T. Nahirniak, O. Pavliv, T. Farionik, and V. Bratyuk, "Influence of 'Thireomagnile' and 'Thyrioton' preparations on the antioxidant status of pregnant cows," Ukr. J. Ecol., vol. 10(1), pp. 122-126, 2020. doi: 10.15421/2020_19.

[15] Clinical Laboratory Services Development Project. Hemoglobin measurement using the MiniGEM 523 analyzer. http://iso15189.ru/data/documents/tmminihem523-sop.pdf, 2016 (accessed 9 May 2019).

[16] V. V. Ermakov, V. A. Safonov, and V. N. Yakimenko, Express method for determining superoxide dismutase activity in blood. Reports of the Moscow Society of Nature Testers. Executive. Moscow: Max-Press Publishing House LLC, 2016.

[17] T. V. Sirota, "New approach to studying the process of adrenaline autoxidation and its use in measuring superoxide dismutase activity," Probl. Med. Chem., vol. 45(3), pp. 263-272, 1999.

[18] V. V. Ermakov, V. N. Danilova, and S. D. Khushvakhtova, Application of HPLC NAM and OFAspectrofluorimetry in determination of biologically active sulfur-containing compounds. in Biogeochemistry of technogenesis and modern problems of geochemical ecology (in two volumes). Barnaul: Barnaul Publishing House, 2015.

[19] B. V. Gutyj, S. D. Mursjka, D. F. Hufrij, I. I. Hariv, N. D. Levkivska, N. V. Nazaruk, M. B. Haydyuk, O. B. Priyma, O. Y. Bilyk, and Z. A. Guta, "Influence of cadmium loading on the state of the antioxidant system in the organism of bulls," Visnyk Dnipropetrovsk Univ. Biol. Ecol., vol. 24(1), pp. 96-102, 2016. doi: 10.15421/011611.

[20] B. Gutyj, V. Stybel, L. Darmohray, Y. Lavryshyn, I. Turko, Y. Hachak, A. Shcherbatyy, I. Bushueva, V.

[22] E. Rahimi, "Lead and cadmium concentrations in goat,
Parchenko, O. Krushelnytska, and A. Kaplaushenko, "Prooxidant-antioxidant balance in the organism of bulls (young cattle) after using cadmium load," Ukr. J. Ecol., vol. 7(4), pp. 589-596, 2017. doi: 10.15421/2017_165.

[21] F. Ota, Y. Kizuka, M. Nakano, Y. Yamaguchi, S. Kitazume, T. Ookawara, and N. Taniguchi, "Sialylation of extracellular superoxide dismutase (EC-SOD) enhances furin-mediated cleavage and secretion," Glycobiology, vol. 27(12), pp. 1081-1088, 2017. doi: 10.1093/glycob/cwx087.

cow, sheep, and buffalo milks from different regions of Iran," Food Chem., vol. 136(2), pp. 389-391, 2013. doi: 10.1016/j.foodchem.2012.09.016.

[23] S. Roggeman, G. De Boeck, H. De Cock, R. Blust, L. Bervoets, "Accumulation and detoxification of metals and arsenic in tissues of cattle (Bos taurus), and the risks for human consumption," Sci. Total Environ., vol. 466-467(1), pp. 175-184, 2014. doi: 10.1016/j.scitotenv.2013.07.007.

[24] R. Sachko, J. Lesyk, I. Luchka, and I. Nevostruyeva, "Contents of heavy metals in food, organism and animal products in the Zacarpathian biogeochemical province," Scientif. Messenger LNU Vet. Med. Biotechn. Ser. Vet. Sci., vol. 18(71), pp. 87-90, 2016.

[25] L. G. Slivinska, A. R. Shcherbatyy, B. O. Lukashchuk, H. O. Zinko, B. V. Gutyj, M. G. Lychuk, B. O. Chernushkin, M. I. Leno, O. I. Prystupa, K. Y. Leskiv, O. I. Slepokura, O. I. Sobolev, O. I. Shkromada, O. S. Kysterna, and O. V. Musilenko, "Correction of indicators of erythrocytopoesis and microelement blood levels in cows under conditions of technogenic pollution,' Ukr. J. Ecol., vol. 9(2), pp. 127-135, 2019.

[26] V. Stybel, O. Fedorovych, and R. Tafiychuk, "Influence of drugs 'Granulated brovermectin' and 'Avesstim' on the level of LOPs and of activity antioxidant system enzymes in hepatopancreas of the same age grass carp affected by monogeneas," Scientif. Messenger LNU Vet. Med. Biotech. Ser. Vet. Sci., vol. 19(82), pp. 50-55, 2017.

[27] T. W. Kekana, U. Marume, M. C. Muya, and F. V. Nherera-Chokuda, "Periparturient antioxidant enzymes, haematological profile and milk production of dairy cows supplemented with Moringa oleifera leaf meal," Anim. Feed Sci. Technol., vol. 268, pp. 114606, 2020. doi: 10.1016/j.anifeedsci.2020.114606. 